\title{
Tusão e experiência: a virtualização no pensamento de Pierre Lévy
}

\author{
Denise da Costa Oliveira Siqueira* \\ Pollyana Coelho da Silva Notargiacomo**
}

\section{Resumo}

Artigo abordando a noção de virtualização na contemporaneidade a partir do pensamento do filósofo francês Pierre Lévy e de exemplos de filmes e romance amplamente divulgados por meios de comunicação. Tema caro à filosofia, a virtualização é tratada hoje em diversos campos do saber e divulgada pelos meios de comunicação de massa, sendo relacionada à globalização da economia e às chamadas novas tecnologias. Essa valorização faz sentido em um período histórico no qual modos de conhecimento e estilos de regulação social ainda pouco estabilizados ganham espaço.

Embora exigindo maneiras de pensar diferentes, as novas tecnologias não provocam ruptura nos modos de transmissão de conhecimento, mas integram-se em um processo que continua incluindo elementos da oralidade, da escrita e da impressão - organizados em uma nova perspectiva. No entanto, por vezes, nesse contexto virtual se torna sinônimo de ilusão e virtualização, de forma ilusória de experimentar. Mas originalmente não eram esses os significados dos termos. Palavras-chave: virtualização, contemporaneidade, novas tecnologias, comunicação.

\section{Introdução}

“... o que é possivel é plausível; ora, enquanto as coisas não acontecem, não estamos dispostos a crer que elas sejam possíveis, mas é claro que são possíveis aquelas que aconteceram, pois não teriam acontecido se não fossem possíveis". ${ }^{1}$

* Professora da UERJ, doutoranda em Comunicação na ECA/USP, autora de A ciência na televisão: mito, ritual e espetáculo (Ed. Annablume, 1999).

** Professora de Informática Educacional do Mackenzie, doutoranda em Educação na FE/USP. Autora da dissertação Comunidade inteligente de jovens: desafios no desbravamento de novos mares metodológicos.

Comun. Inf., v. 3, n. 2, p. 181-196, jul./dez. 2000 
"Você já teve a sensação de que não tem certeza se está acordado ou ainda dormindo?"2

Tema caro à filosofia, a virtualização é tratada hoje em diversos campos do saber e divulgada pelos meios de comunicação de massa. Vários fatores são importantes para entender a discussão sobre a virtualização e, por extensão, sobre a contemporaneidade. Dentre esses fatores sociais, culturais, econômicos e históricos, podese destacar a consolidação de uma rede urbana que se estende sobre o campo, o deslocamento das atividades econômicas para o setor terciário, uma maior participação das pesquisas científicas em atividades produtivas e modos de vida. Esses fatores, associados ao incremento e à banalização de novas tecnologias e à construção de um novo imaginário do espaço e do tempo, parecem levar o termo virtual e seus derivados a ocupar importante papel nas culturas urbanas contemporâneas.

O largo emprego do termo virtual ocorre ao mesmo tempo em que a globalização da economia é valorizada por determinados setores da sociedade e faz com que poder estar em contato com vários lugares distantes simultaneamente ou simular operações em um espaço virtual, sem ter que arcar com prejuízos concretos, seja considerado vantagem por esses setores.

Essa valorização faz sentido em um período histórico no qual modos de conhecimento e estilos de regulação social ainda pouco estabilizados ganham espaço. Trata-se de um momento em que uma nova relação com o universal (macro) e o quântico (micro) se estrutura, levando a repensar o papel da humanidade.

É mais um momento em que, na história da cultura, o surgimento de novas tecnologias intelectuais introduz outras formas de saber. Embora exigindo maneiras de pensar diferentes, as novas tecnologias não provocam uma ruptura, mas integram-se em um processo que continua incluindo elementos da oralidade, da escrita e da impressão - organizados em uma nova perspectiva.

Nesse contexto, virtual ganhou, então, significado de ilusão e virtualização, de forma ilusória de experimentar. No entanto originalmente não eram esses os significados dos termos. Este texto tem como objetivo apontar questões sobre a temática da virtualização na contemporaneidade em um estudo do pensar do filósofo Pierre Lévy.

Comun. Inf., v. 3, n. 2, p. 181-196, jul./dez. 2000 


\section{0 virtual e a ilusão}

Os meios de comunicação exploram o tema da virtualização com superficialidade, divulgando um modo de vida tecnológico e acelerado, ao qual a maior parte da audiência não tem acesso.

Nos meios de comunicação, seja em espaços de ficção ou de informação jornalística, virtual tem a conotação de ilusão. Mas a questão da virtualização abarca mais problemáticas do que as levantadas pela mídia. Na realidade, velocidade é um termo-chave para se lidar com as mudanças na contemporaneidade. Essa velocidade é possível porque a virtualização é a base das mudanças em curso.

A ficção científica vem explorando a questão da virtualidade em filmes como Matrix e em livros como Neuromancer. Em Neuromancer surgiu o termo ciberespaço e Matrix se inspira no livro para criar uma narrativa, na qual os personagens buscam descobrir se são reais ou se estão imersos em alguma forma de realidade virtuall.

Mas antes de temer ou aprovar processos de virtualização, é importante realizar um esforço para compreender o conceito. Na análise do filósofo Pierre Lévy, o virtual tem uma pequena afinidade com o falso, o ilusório ou com o imaginário (1996, p.12), mas a virtualização não se constitui, como vulgarmente se considera, na ausência de existência e nem é sinônimo de desmaterialização. "Na filosofia escolástica, é virtual o que existe em potência e não o ato. $O$ virtual tende a atualizar-se, sem ter passado, no entanto, à concretização efetiva ou formal" (Op.cit., p. 15).

$\mathrm{Na}$ acepção de Lévy, o virtual não se opõe ao real, mas ao atual. Virtualidade e atualidade são apenas duas maneiras de ser diferentes. O possível já está todo constituído e se realizará sem que nada mude em sua determinação nem em sua natureza (Ibid). E um real latente:

"O possível é exatamente como o real; só lhe falta a existência. A realização de um possível não é uma criação, no sentido pleno do termo, pois a criação implica também a produção inovadora de uma idéia ou de uma forma. A diferença entre possível e real é, portanto, puramente lógica.

Já o virtual não se opõe ao real, mas sim ao atual. Contrariamente ao possível, estático e já constituído, o virtual é como o complexo problemático, o nó de tendências ou de forças que acompa-

Comun. Inf., v. 3, n. 2, p. 181-196, jul./dez. 2000 
nha uma situação, um acontecimento, um objeto ou uma entidade qualquer, e que chama um processo de resolução: a atualização" (LÉVY, 1996, p.16).

Embora consagrando a virtualização como concorrente da atualização, o autor apresenta o real, o possível e o atual como complementares, e não opostos ao virtual, formando juntos quatro pólos, ou quatro modos de ser. Assim,

\begin{abstract}
"Possível e virtual têm evidentemente um traço em comum que explica sua confusão tão frequiente: ambos são latentes, não manifestos. Anunciam antes um futuro e oferecem uma presença. O real e o atual, em troca, são um e outro patentes e manifestos. Desdenhando as promessas, estão presentes e claramente presentes" (Op.cit., p.136).
\end{abstract}

Possível, real, virtual e atual são estados que se relacionam, atuando em cada fenômeno concreto, mas têm maneiras de ser diferentes. O possível assemelha-se com o que é real, enquanto o virtual tem a ver com o que é atual. A articulação do virtual e do atual anima a dialética do acontecimento, do processo, da criação. Por outro lado, o processo de potencialização e de realização só adquire sentido na dialética da atualização e da virtualização.

Lévy entende que a virtualização é o movimento pelo qual se constitui e permanece a espécie humana. Sua abordagem difere daquela de autores críticos, como Baudrillard e Virilio, na medida em que apresenta a virtualização como algo pertencente ao mundo humano. Sua abordagem também é distinta da visão espetacular que os meios de comunicação geralmente mostram sobre o virtual: "Longe de circunscrever o reino da mentira, o virtual é precisamente o modo de existência de que surgem tanto a verdade como a mentira" (Op.cit., p. 148).

Exemplo de imersão explorada pela ficção pode ser encontrado no livro Neuromancer, de William Gibson. Nele, Case, um hacker, é contratado para invadir um poderoso sistema de inteligência artificial. Para essa aventura, ele conta com Molly, uma guarda-costas que possui implantes biônicos, e com McCoy, outro hacker que, apesar de já ter morrido, interage com Case por meio de um CD-ROM, no qual estão armazenadas suas experiências e memória. O personagem relata sua entrada no ciberespaço, como outra pessoa. Liga o computador e sente:

Comun. Inf., v. 3, n. 2, p. 181-196, jul./dez. 2000 
"Um salto abrupto para a carne de outra pessoa. A matriz desaparecida, uma onda de som e cor... A garota caminhava por uma rua movimentada, ao longo de postos que vendiam software com desconto; os preços escritos a caneta de feltro em folhas de plástico, fragmentos de música saídos de inúmeros alto-falantes; cheiro de urina, monômetros livres, perfume, empadas fritas de camarão. Por alguns assustadores segundos, lutou desesperadamente para controlar o corpo da moça. Nada feito; com um ato de vontade, entrou de novo em passividade, tornando-se apenas o passageiro atrás dos olhos dela" (Gibson, 1991, p. 59).

O filme Matrix, de Andy e Larry Wachowski, também joga com a noção de virtual e com a possibilidade de imersão total nesse virtual. Na história contada, mediante a ingestão de comprimidos, é possível enxergar o mundo de outro ponto de vista. A pílula vermelha transporta para uma nova realidade enquanto a azul mantém a aparente "vida cotidiana". O que o protagonista vem a descobrir é que o que parece real não necessariamente oé. $\mathrm{O}$ artificial, alcançado por intermédio da pílula vermelha, é que talvez seja. No fundo, é mais uma metáfora que aborda a temática do mito da caverna de Platão, e que faz pensar: o que é o real?

Matrix representa o simulacro, a hiperrealidade formada a partir de uma realidade que é mais real do que os modelos socioculturais sobre o que seja a realidade "verdadeira". O filme leva a refletir sobre as imposições do sistema, seja ele capitalista ou espelhado no novo "tecnopólio" do personagem Neil Postman. Com isso, se dá o triunfo do simulacro que apresenta a superioridade do falso sobre o real. Isso aparece no filme com o personagem Cypher, o "traidor" que busca retornar para o mundo da Matrix e fingir que a realidade nunca existiu.

Deixando a ficção e retomando o campo conceitual, pode-se pensar que Matrix é uma metáfora da contemporaneidade. No filme, o planeta é um deserto, o que sobrou depois da última guerra. As máquinas preservam os homens, que servem de fonte de energia. Eles são mantidos em "realidade virtual" para não saber "a verdade" sobre sua condição de escravos. Nesse sentido, pode-se citar Lemos quando escreve: "Nessa civilização do virtual, não somos mais nós que pensamos o mundo, mas o mundo que nos pensa. Nós traduzimos o mundo em 'bits' e, ao mesmo tempo, os 'bits' nos traduzem em infor-

Comun. Inf., v. 3, n. 2, p. 181-196, jul./dez. 2000 
mação. Somos todos pontos de troca nessa estrutura rizomática de informações."

Outro filme que explora a temática da simulação ou da imersão total em um espaço não "real" é $13^{\circ}$ andar. A história trata de dois pesquisadores que trabalham em um projeto de cidade virtual utilizando, para isso, tecnologia de inteligência artificial. A cidade é uma recriação de Los Angeles em 1937, refletindo o saudosismo de um dos técnicos. Nesse ambiente é possível fazer uma imersão, mergulhar e interagir com os personagens. No entanto, o que está por trás é que o mundo que se acredita real e gerador do virtual também é virtual e foi criado a partir do perfil de personagens reais. É o virtual do virtual.

Os três exemplos citados anteriormente explicitam uma vontade de analisar, entender o real a partir de metáforas com o virtual ou o ilusório. Os filmes e o livro também apontam para riscos de não se conseguir mais distinguir entre o que é ilusão e o que é experiência física. Adriano Rodrigues usa a metáfora do vidro para explicar a perda de referencial provocada pelo paradoxal conceito de "realidade virtual":

\begin{abstract}
"Aquilo que até agora tornava visíveis os dispositivos de simulação e de construção de simulacros era precisamente o limite da transparência, obrigando a parar o olhar naquilo que opacifica a visibilidade. Só nos damos conta da existência do vidro na medida em que ele não é completamente translúcido. É para tornar os vidros visíveis e deste modo prevenir eventuais acidentes que se limita a sua transparência, colocando por exemplo autocolantes opacos nas portas de vidro. Ao tornar a realidade virtual totalmente transparente, as actuais tecnologias da informação tendem a tornar-se imperceptíveis. Podemos por isso dizer que o outro reverso da transparência é a cegueira que induz em relação ao dispositivo"' (1999, p. 92).
\end{abstract}

A questão do simulacro, à qual se refere Rodrigues, foi desenvolvida por Jean Baudrillard em Simulacros e simulação. Segundo Baudrillard (1991), o simulacro é uma forma de imagem. Inicialmente, o signo reflete uma realidade profunda. Em seguida, essa realidade profunda passa a ser deformada pelo signo. No estágio subseqüente, a ausência da realidade profunda passa a ser representada por uma máscara. E, finalmente, a fase do simulacro define-se pela total falta de relação entre a realidade e o signo ou imagem presente.

Comun. Inf., v. 3, n. 2, p. 181-196, jul./dez. 2000 
Em sociedades nas quais os meios de comunicação de massa ocupam importante espaço na cultura, os simulacros tendem a se multiplicar, levando a formar juízos sobre realidades com as quais nunca se conviveu ou nunca se experimentou.

\title{
3 Ciberespaço: a virtualização da experiência
}

Hoje, quando se pensa em virtual, não se pode deixar de refletir sobre o ciberespaço, local de virtualização do corpo, da economia, da inteligência, da experiência. A informática contemporânea, durante muito tempo entendida somente como computador e programas, abriu lugar a um espaço de comunicação navegável, centrado nos múltiplos fluxos de informação, o ciberespaço:

\begin{abstract}
"O computador não é um centro mas um pedaço, um fragmento da trama, um componente incompleto da rede calculadora universal. Suas funções pulverizadas impregnam cada elemento do tecnocosmo. No limite, só há hoje um único computador, um único suporte para texto, mas tornou-se impossível traçar seus limites, fixar seus limites, fixar seu contorno. É um computador cujo centro está em toda parte e a circunferência em nenhuma, um computador hipertextual, disperso, vivo, ululante, inacabado, virtual, um computador de Babel: o próprio ciberespaço" ( LÉVY, 1996, p.47).
\end{abstract}

O ciberespaço, assim, fundamenta-se na desterritorialização do texto, da economia, das finanças, do trabalho, do mercado, da arte, enfim, da experiência humana em suas várias representações.

Nele, parece ser maior a tendência de substituir experiências físicas por ligações virtuais. Para isso, bastaria que o texto, os dados, as informações e as imagens existissem fisicamente uma única vez na memória de um computador conectado à rede. Assim, seria possível graças a um conjunto de vínculos, de milhares, ou mesmo, de milhões de percursos -, a partir dos websites e dos hiperdocumentos on-line, "seguir os fios dos diversos universos subjetivos"(Op.cit., p. 48).

No processo de virtualização e no de constituição do ciberespaço, um elemento é fundamental: o hipertexto. O hipertextoé constituído de nós entrelaçados por conexões. Cada um dos nós pode ser construído por diferentes mídias (palavras, imagens, gráficos, sons e mesmo por outros hipertextos). Com isso, ocorre uma ligação não-

Comun. Inf., v. 3, n. 2, p. 181-196, jul./dez. 2000 


\section{8}

linear entre as partes, possibilitando infinitas opções de consultas ou de "navegação" hipertextual.

O hipertexto está em constante mutação. Por seu dinamismo interno, oferece infinitas configurações a quem o consulta, gerando um metatexto fluido e caleidoscópico. No contexto hipertextual, a velocidade é um elemento relevante, pois faz perder o senso de (não) linearidade que a passagem quase instantânea de um nó a outro na rede poderia provocar. Navegar nos hipertextos das redes de computadores é provocar a sensação de perda do referencial espaço-temporal. O próprio verbo utilizado para designar o procedimento daquele que navega pela rede é to browse, que também significa "recolher" e "dar uma olhada".

O hipertexto pode ser interessante para o trabalho de equipe, pois contribui para a organização, a argumentação, a criação, a discussão e o planejamento de forma coletiva. A troca de informações (ampliadas por Lévy para atos de linguagem, em As tecnologias da inteligência) dentro do chamado "groupware" tem o intuito de coordenar a ação. O groupware é uma tecnologia desenvolvida para auxiliar o trabalho colaborativo no que se refere à comunicação, coordenação, cooperação, resolução de problemas e negociação, por meio de ferramentas como correio eletrônico (email), "newsgroup" e "chat" (bate-papo), que possibilitam o trabalho síncrono, assíncrono e desterritorializado.

Assim, as coletividades dos "groupwares" teriam um funcionamento de interlocução, complementado pelo vínculo de cada argumento com outros documentos pertinentes. Isso permite uma escrita coletiva (nãolinear e não-estática), inserida em um novo modo informacional, que constrói uma bagagem referencial complexa, associativa, compartilhada, unificada hipertextualmente para a criação de novas associações na rede.

Para dar continuidade ao estudo de idéias propostas por Lévy, faz-se necessário compreender também o conceito de inteligência: um conjunto de aptidões cognitivas de percepção, lembrança, aprendizado, imaginação e raciocínio. Esse conjunto de aptidões tem um caráter social, responsável pelo estímulo às capacidades cognitivas. Conseqüentemente, pode-se dizer que a inteligência desenvolve-se socialmente, no sentido de ter o outro como fonte de conhecimento. Para justificar e exemplificar esse raciocínio, Lévy cita (no livro $O$ que éo virtual?) os signos, ferramentas coletivas que permitem o funciona-

Comun. Inf., v. 3, n. 2, p. 181-196, jul./dez. 2000 
mento intelectual e trazem uma bagagem acumulada de pesquisas, criações, descobertas e experiências.

É a partir do pressuposto de que não há ser humano com sabedoria plena (todos possuem conhecimento específico) que se pode formar um conceito de intelectual coletivo:

\begin{abstract}
“(...)espécie de sociedade anônima para qual cada acionista traz como capital seus conhecimentos, suas navegações, sua capacidade de aprender e de ensinar. (...) Esse sujeito transpessoal não se contenta em somar as inteligências individuais. Ele faz florescer uma forma de inteligência qualitativamente diferente, que vem se acrescentar às inteligências pessoais, uma espécie de cérebro ou hipercórtex"(LÉVY, 1998, p.94).
\end{abstract}

Fazendo um paralelo com a série de livros Duna, de F. Herbert, pode-se dizer que tal sociedade anônima, mencionada por Lévy, seria como as feiticeiras de Herbert, que acumulam em si as vidas de todas as feiticeiras anteriores. Ao morrer, elas transmitem às suas sucessoras toda essa "inteligência coletiva" acumulada. Como escreveu Herbert, elas constituem o máximo de empatia: ser mais de uma pessoa ao mesmo tempo. "Não é telepatia, mas consciência mútua" (1987, p. 450).

Esse paralelo é significativo, porque Lévy faz uma distinção entre inteligência coletiva e coletivo inteligente, sendo a primeira constituída da parte distributiva da informação, do mergulho em um hipercórtex como a Internet. Quanto ao coletivo inteligente, está vinculado mais diretamente ao caráter de alimentação intelectual do todo e de cada uma das partes. Assim, pode-se dizer que o coletivo inteligente (todos que têm acesso às redes de computadores, por exemplo) abastece com informações a inteligência coletiva e vice-versa. É um processo, um fluxo contínuo.

A inteligência coletiva existe apenas em comunidade, mas sua existência não implica em destruição ou fusão das inteligências individuais. As duas esferas, a coletiva e a individual, coexistem. Dessa forma, através de um espírito cooperativo, a criatividade individual contribuiria com o conjunto de conhecimento coletivo.

O avanço na comunicação não-mediática, tendo em vista a comunicação de todos-para-todos - em vez do modelo "mass mediático" do um-para-todos - é fundamental para dar base às novas instâncias da inteligência coletiva.

Comun. Inf., v. 3, n. 2, p. 181-196, jul./dez. 2000 
Para o desenvolvimento da inteligência coletiva, e mesmo para o surgimento de outras formas de inteligência coletiva, são necessárias a interação e a valorização da consciência individual junto à inteligência grupal. A valorização das singularidades criadoras, processo que sofre a ação retroalimentadora a cada emergência de uma nova geração, vai enriquecer a inteligência coletiva.

Enquanto as conversas cotidianas se realizam sem estrutura bem definida, apresentam pouca hierarquia de assuntos e diminuta organização interna, provocadas pelos limites da memória humana, na comunicação em "groupware", uma espécie de discurso coletivo, as falas pessoais se integram em um discurso plural, mais articulado.

A escrita virtual exige a formação de equipes de autores, em um processo de inteligência coletiva, como em um processo de montagem de espetáculo. Trata-se de algo muito distante da redação clássica, em que o autor, individualmente, se preocupa apenas com a coerência de um texto linear e estático. Sem esse trabalho coletivo seria impensável, por exemplo, a produção de uma enciclopédia em CD-ROM. E, nessa perspectiva, Lévy compara os novos escritores de hipertexto com os grandes impressores do século XVI, que eram ao mesmo tempo letrados, humanistas, técnicos e exploradores de um modo de organização do saber (1993, p.104).

Com a produção intelectual virtual e coletiva, questões de autoria, de preservação de direitos autorais e problemas correlatos exigem não apenas novos procedimentos, mas concepções. No ciberespaço, o leitor também é autor e o consumidor torna-se co-produtor da informação, com produtos e serviços cada vez mais interativos. Isso faz com que, em termos econômicos, a produção de valor agregado se desloque para o lado do "consumidor", fazendo com que se substitua a noção de puro consumo pela de co-produção aliada ao consumo de mercadorias ou de serviços interativos.

A exploração econômica da propriedade sobre a informação, na forma de direitos autorais, também se adapta à nova realidade, sem que se abandone totalmente qualquer pretensão à propriedade sobre os programas e a informação, o que "seria arriscar-se a voltar aquém da invenção do direito autoral e da patente, à época em que as idéias suadas dos trabalhadores intelectuais podiam ser bloqueadas por monopólios ou apropriadas sem contrapartida por potências econômicas ou políticas" (LEVY, 1996, p.64).

Comun. Inf., v. 3, n. 2, p. 181-196, jul./dez. 2000 
Para Lévy, não se deve suprimir completamente o direito autoral, mas substitui-lo por sistemas de contagem contínua do consumo de informações pelos usuários finais. Uma das propostas que já está sendo veiculada a esse respeito é a dos livros eletrônicos, os " $e$-books". Esses livros são apresentados no formato digital (Portable Document Format - PDF) para download. Com isso, algumas empresas e editoras parecem acreditar que haverá maior difusão dos títulos, pois a disponibilização on-line reduz os custos e, ao mesmo tempo, mostra outros formatos para o livro.

Um livro on-line pode ser constantemente revisto, atualizado, ampliado e também abre possibilidades como a discussão direta entre autor e leitores, que, em última instância, tornam-se co-autores à medida que fazem críticas, apresentam pontos de vista e contribuem para a constante discussão de caminhos hipertextuais de leitura.

Escritores de best-sellers, com grandes vendagens em vários países, começam a investir também no livro eletrônico. Um exemploé o recente Riding the Bullet, trabalho do escritor Stephen King, lançado somente no formato de $e$-book em março de 2000 , com 66 páginas. $\mathrm{O}$ download era gratuito e podia ser feito pelo endereço eletrônico da livraria Amazon (http://www.amazon.com/exec/obidos/subst/ promotions/stephen-king/stephen-king.html/ref=aps_ra/lo33006730-0539865). Paralelamente, começam a surgir pequenas "editoras" eletrônicas que visam a publicar obras que não conseguiram espaço nas editoras de livros impressos.

No entanto vale notar que o formato do livro impresso, o códex, ainda é mais confortável e portátil que sua versão digital. Esta se adequa melhor a materiais de referência, como dicionários e enciclopédias, os quais o leitor consulta, mas não mantém uma leitura linear de toda a obra. Assim, para novas mídias, novas utilidades.

\section{Velocidade e desterritorialização}

A aceleração das comunicações trouxe consigo crescimento da mobilidade física. Atualmente, as pessoas têm mais acesso a veículos que possibilitam seu transporte a longas distâncias em menos tempo do que nos séculos passados. A virtualização viabiliza encontros sem necessidade de mobilização ou contato físico. Mas, ao mesmo tempo, promove encontros que antes não seriam possíveis e encontros tendem a levar à necessidade de contatos físicos - tais como reuniões

Comun. Inf., v. 3, n. 2, p. 181-196, jul./dez. 2000 
para assinaturas de contratos - e que geram locomoção física. O que ocorre com a generalização do transporte e aceleração das comunicações é o mesmo que acontece com a virtualização da sociedade, a mesma tensão em prescindir da presença física para continuar atuando na comunidade e, dessa forma, participando da ação cultural (LÉVY, 1996, p.23).

A comunidade virtual se organiza através de sistemas de comunicações telemáticas. Embora não-presentes em termos espaciais tradicionais - a questão da distância tem sua importância reduzida -, seus membros estão reunidos pelos mesmos interesses:

\begin{abstract}
“Apesar de 'não-presente', essa comunidade está repleta de paixões e de projetos, de conflitos e de amizades. Ela vive sem lugar de referência estável: em toda parte onde se encontram os seus membros móveis... ou em parte alguma. A virtualização reinventa uma cultura nômade, não por uma volta ao paleolítico nem às antigas civilizações de pastores, mas fazendo surgir um meio de interações sociais onde as relações se reconfiguram com um mínimo de inércia" (LÉVY, 1996, p. 21).
\end{abstract}

Todavia a sociedade está pagando um preço significativo pelo desenvolvimento acelerado dos meios de transporte e da própria velocidade, pois, embora encurtando distâncias e reduzindo espaços, essa aceleração provoca degradação no ambiente tradicional. O equilíbrio entre novas tecnologias e ambiente só pode ser alcançado após análise crítica e implementação de estratégias educativas e fiscalizadoras o que nem sempre é prioridade e implica em custos.

A questão do acesso às novas tecnologias tem levado também à reflexão sobre sociedade e educação. A democratização não passa apenas pela oferta de acesso gratuito à Internet ou à inteligência coletiva (como a publicidade dos provedores gratuitos costuma apregoar). É necessário que sejam implementadas, conjuntamente, políticas educacionais que possam capacitar as pessoas para a utilização do computador e da Internet. Um esforço nesse sentido é o Projeto da Sociedade da Informação, que parte da "concepção de uma estratégia nacional para estimular a adequada inserção da sociedade brásileira na Sociedade Global da Informação", com objetivo de traçar um projeto nacional que viabilize a infra-estrutura e serviços para o "desenvolvimento de uma nova geração de redes Internet, com benefícios estendidos a toda a sociedade brasileira". ${ }^{4}$

Comun. Inf., v. 3, n. 2, p. 181-196, jul./dez. 2000 
Assim, a responsabilidade continua sendo do homem, jamais da técnica em si.

Nesse contexto de inovações tecnológicas, o turismo, as comunicações e as finanças ocupam importante espaço na economia; no entanto, os bens econômicos mais significativos são as informações e o conhecimento.

Até a metade do século XX, parecia haver uma relação direta entre as competências adquiridas, mediante a formação profissional e o desempenho individual, baseando-se os conhecimentos na quantidade de conteúdos adquiridos, em escala seqüencial e cumulativa. Hoje, no entanto, "novas técnicas ou novas configurações socioeconômicas podem a todo momento recolocar em questão a ordem e a importância dos conhecimentos" (LÉVY, 1996, p. 55).

Desse modo, uma formação universitária ou técnica não garante mais o domínio permanente de conhecimento na área, e sim, domínio provisório.

Mas as novas tecnologias digitais não atuaram apenas no plano econômico e no do conhecimento. As mudanças também atingiram o plano da arte e da criação. A digitalização e os suportes das contemporâneas tecnologias dão novo potencial às artes em geral, facultando uma reunião de funções artísticas e uma nova relação entre sujeito e obra. $^{5}$

Esse processo ocorreu com as artes visuais. A digitalização permitiu novos processos de montagem e sincronização. A síntese da imagem se faz com a superação do suporte físico, como ocorre com o som digital. A infografia, que reúne as técnicas de tratamento e de criação de imagens, representa certamente algo mais que uma simples automatização da pintura ou do desenho, sendo a imagem digital indispensável para a simulação que, por sua vez, é fundamental para a pesquisa científica.

\section{Considerações finais}

No contexto das recentes tecnologias de comunicação, formou-se um espaço de inteligência coletiva no qual inovações científicas e técnicas circulam velozmente, repercutindo na arte, na economia, na comunicação, na vida cotidiana, no trabalho, nas relações espaciais e corporais. Esse "locus" é o ciberespaço, ferramenta representante desta era.

Comun. Inf., v. 3, n. 2, p. 181-196, jul./dez. 2000 
Devido ao fenômeno conhecido como explosão da informação, na metade do século XX, a produção e a circulação de mensagens e informações alcançaram volumes nunca antes previstos ou imaginados. O ciberespaço parece tornar-se o sistema, no qual toda essa informação pode ser navegada, a fim de que haja a promoção e construção de coletivos inteligentes, permitindo desenvolvimento e ampliação das potencialidades sociocognitivas individuais.

Assim, o mundo virtual seria uma ferramenta de (auto)conhecimento e formação de grupos humanos. Em tese; o mundo virtual possibilitaria o pensar conjunto, num ambiente de dispersão geográfica (dos integrantes do grupo), para a constituição de um cérebro cooperativo. Devido a esse avanço tecnológico, tem-se visto que a rede (Web) pode ser considerada um objeto catalisador da inteligência coletiva.

Exemplificando, verifica-se atualmente que as informações disponibilizadas "on line" ou no ciberespaço geralmente compreendem uma gama desterritorializada de textos e outras mídias (imagens e sons, por exemplo), que pode ser complementada por inúmeros hipertextos, que refletem pontos de vista pessoais sobre determinados temas, propiciando a renovação/atualização contínua.

Dessa forma, a inteligência coletiva estaria disponível em tempo integral e seria infinita, pois o mundo virtual encontra-se em constante e incessante atividade. Por conseguinte, passa-se a uma negociação interativa permanente. Assim, a World Wide Web "é um tapete de sentido tecido por milhões de pessoas e devolvido sempre ao tear. Da permanente costura pelas pontas de milhões de universos subjetivos emerge uma memória dinâmica, comum, 'objetivada', navegável" (LÉVY, 1996, p.114).

A Internet e seus bancos de dados não devem ser entendidos como repositório de todo conhecimento, mas espaço para reunião de uma série de saberes utilizáveis, perecíveis e transitórios, colocando à disposição, rapidamente, elementos para a consulta e a tomada de decisões.

Habilidades e representações continuarão sendo transmitidas e transformadas de forma oral nas diversas redes sociais. A criação de novos suportes para informação não conseguiria provocar o desaparecimento do livro e das formas tradicionais de preservação da cultura e da sociedade.

Desse modo, em tese, o progresso tecnológico e interativo conduziria a humanidade a novos estilos de saber, cuja expressão

Comun. Inf., v. 3, n. 2, p. 181-196, jul./dez. 2000 
hipertextualizada no ciberespaço não deveria - e a rigor, nem poderia - legitimar formas de exclusão de grupos e indivíduos cujas existências prescindem de sua inserção na inteligência coletiva. Essa leitura dá prosseguimento à proposta de emancipação do homem do lluminismo. No entanto, ao final do século XX, a utopia cedeu lugar ao desencanto. Coexistem elementos bárbaros, a globalização, os fanatismos, as máfias, a fome, o ciberespaço e o analfabetismo. O projeto da inteligência coletiva é uma nova utopia, embora ainda reservada àqueles que tiverem acesso ao ciberespaço.

\title{
Agradecimentos
}

A autora agradece os colegas da ECA/USP: Ana Maria Dalla Zen e Carlos Eduardo Abbud, pela colaboração.

\begin{abstract}
The notion of virtuality on modern society is discussed in this work departing from the thoughts of the french philosopher Pierre Lévy and from examples of movies and novels widely broadcasted by the media. This concept, precious to the area of philosophy, is nowadays employed in many other fields of knowledge, is largely used by the media and is connected to the globalization of the economy and the so called new technologies. The broader usage of this concept should come as no surprise in a historical period in which new technologies and new social regulation mechanisms, not yet fully stabilized, gain space.

Although demanding different thinking paths, the new technologies of communication do not lead to ruptures in the way knowledge is transmitted, being, instead, integrated in a process that keeps comprising oral and written elements, now organized under a fresh perspective. It should be noticed that sometimes, in this context, virtual could be taken for illusory, although this was not the original meaning of the term.

Kewwords: virtuality, new technologies, communication.

\section{Notas}

1. Aristóteles. Poética, p. 35 .

2. No filme Matrix, frase dita por Neo, o hacker protagonista interpretado pelo ator Keanu Reeves.

3. LEMOS, A. “Civilização do Virtual”. A Página dos Cyborgs. Disponível em: <http://www.facom.ufba.br/pesq/cyber/lemos/cap2.html>. Acesso em: 14 maio 1998.
\end{abstract}

Comun. Inf., v. 3, n. 2, p. 181-196, jul./dez. 2000 
4. CONSELHO NACIONAL DE CIÊNCIA E TECNOLOGIA. "Ciência e tecnologia para a construção da sociedade da informação no Brasil", Resumo Executivo - Versão 3. Disponível em: <http://www.cct.gov.br/gtsocinfo/atividades/docs/versao3/resumo.htm>. Acesso em: 18 abr. 2000.

5. Sobre o tema da arte e das novas tecnologias, ver a coletânea: DOMINGUES, Diana. A arte do século XXI: a humanização das tecnologias. [São Paulo]: Unesp, 1997.

\section{Referências}

ARISTÓTELES. Poética. In: DUARTE, Rodrigo (Org.). O belo autônomo: textos clássicos de estética. Belo Horizonte: UFMG, 1997. cap. 1-12, p. 25-38.

BAUDRILLARD, Jean. Simulacros e simulação. Lisboa: Relógio d'Água, 1991. CONSELHO NACIONAL DE CIÊNCIA E TECNOLOGIA (Brasil). Ciência e tecnologia para a construção da sociedade da informação no Brasil, Resumo Executivo - Versão 3. Disponível em: <http://www.cct.gov.br/gtsocinfo/atividades/docs/versao3/resumo.htm>. Acesso em: 18 abr. 2000.

DOMINGUES, Diana. (Org.). A arte no século XXI: a humanização das tecnologias. São Paulo: Unesp, 1997.

GIBSON, William. Neuromancer. São Paulo: Aleph, 1991. (Coleção Zenith, 5). HERBERT, F. Duna. Rio de Janeiro: Nova Fronteira, 1987.

LEMOS, André. Civilização do Virtual. In: . A Página dos Cyborgs. Disponível em: <http://www.facom.ufba.br/pesq/cyber/lemos/cap2.html>. Acesso em: 14 maio 1998.

LÉVY, Pierre. O que éo virtual? São Paulo: Ed. 34, 1996.

. As tecnologias da inteligência: o futuro do pensamento na era da informática. São Paulo: Ed. 34, 1993.

A inteligência coletiva: por uma antropologia do ciberespaço. São Paulo: Loyola, 1998.

RODRIGUES, Adriano Duarte. Contributos para uma genealogia do virtual. Real vs. Virtual - Revista de Comunicação e Linguagens, Lisboa, n. 25/26, p. 87-95, 1998/1999.

Comun. Inf., v. 3, n. 2, p. 181-196, jul./dez. 2000 